\title{
The Research of a Staircase Constructed Project- oriented Teaching Method from the Perspective of Total Quality Management
}

\author{
Da Si \\ School of Economic and Trade Management \\ Tianjin Sino-German University of Applied Sciences \\ Tianjin, China
}

\begin{abstract}
In China, many vocational schools attempt to adopt action-based "project-oriented teaching method" to organize teaching activities. However, in the course of teaching arrangement, the problem of "acclimatized" appeared to the method. Therefore, this study proposes the staircase constructed project-oriented teaching method from the perspective of total quality management: the ability development of applicationoriented technological students, which take staircase constructed teaching project as carrier, grade-by-grade benchmarking study as method and total quality management as the guiding ideology of the project-oriented teaching management, so as to meet the learning needs of students at different levels through the method.
\end{abstract}

Keywords-total quality management; staircase constructed project-oriented teaching; benchmarking study

\section{INTRODUCTION}

Innovation-driven development is a significant national strategy, to implement which, it requires not only a large number of top innovative master-level talents, but also numerous application-oriented technological talents who are equipped with modern science and technology knowledge and expertise [1], working in the frontline of modern production service.

In that context of popularization and universalization of higher education in China, the implementation of projectoriented teaching is of great significance for the development of application-oriented technological talent. In our country, many vocational schools try to adopt action-oriented "projectoriented teaching method" to organize teaching. This study tries to explore the effective project-oriented teaching mode suitable for the current situation of Chinese applicationoriented technological talents and the needs for talent development.

\section{PROBLEMS IN THE PROJECT-ORIENTED TEACHING}

\section{METHOD FOR DEVELOPMENT OF APPLICATION-ORIENTED} TECHNOLOGICAL TALENTS IN CHINA

Due to different learning abilities of Chinese applicationoriented technological school students, polarization situation of students may occur in the implementation of the project. For students with good learning base, the "project-oriented teaching method" is effective and popular, the student's ability will be improved in the course of completing the project; for students with relatively weak learning base, the learning effect is not obvious, mainly including the following problems:

First, the difficulty of the project affects learning interest. Students with poor basic lack learning initiative and ability of independent thinking. In previous studies, it mainly depends on teachers' teaching. Therefore, it is a bit hard to make students to adapt such student-based "project-oriented teaching" and they have no much interest in such study.

Second, the difficulty of the project affects learning effect. For students with weak foundation, it is difficult to complete the project and feel "have no ways of doing it", which leads to "never do it again" upon completion of the project. It will cause that the project-oriented teaching does no give them selfconfidence as expected, but blows their self-confidence and influences their initiative for the follow-up learning work.

\section{CONSTRUCTION OF STAIRCASE CONSTRUCTED PROJECT-ORIENTED TEACHING METHOD FROM THE PERSPECTIVE OF TOTAL QUALITY MANAGEMENT}

In view of the necessity of the cultivation of talents in science and technology in our country, in order to play a better role of "project-oriented teaching method" and equip all the students with competent abilities to corresponding job, the study puts forward the staircase constructed project-oriented teaching method from the perspective of total quality management: the ability development of application-oriented technological students, which taking staircase constructed teaching project as carrier, grade-by-grade benchmarking study as method and total quality management as the guiding ideology of the project-oriented teaching management.

\section{A. Design of Staircase Constructed Project-oriented Teaching}

In the course of teaching, 3 types of 6-staircase teaching projects are designed according to the students' different learning base and learning ability based on the principal of individualized teaching. Teaching projects in different stairs meet the learning and practical needs of the students at different levels, promote their abilities step by step, which can 
not only train the first-rate students through high-level project, but also take care of the learning interest and ability of the lessadvanced students, and at the same time, it can meet the

general learning needs of middle school students as shown in "Fig. 1".

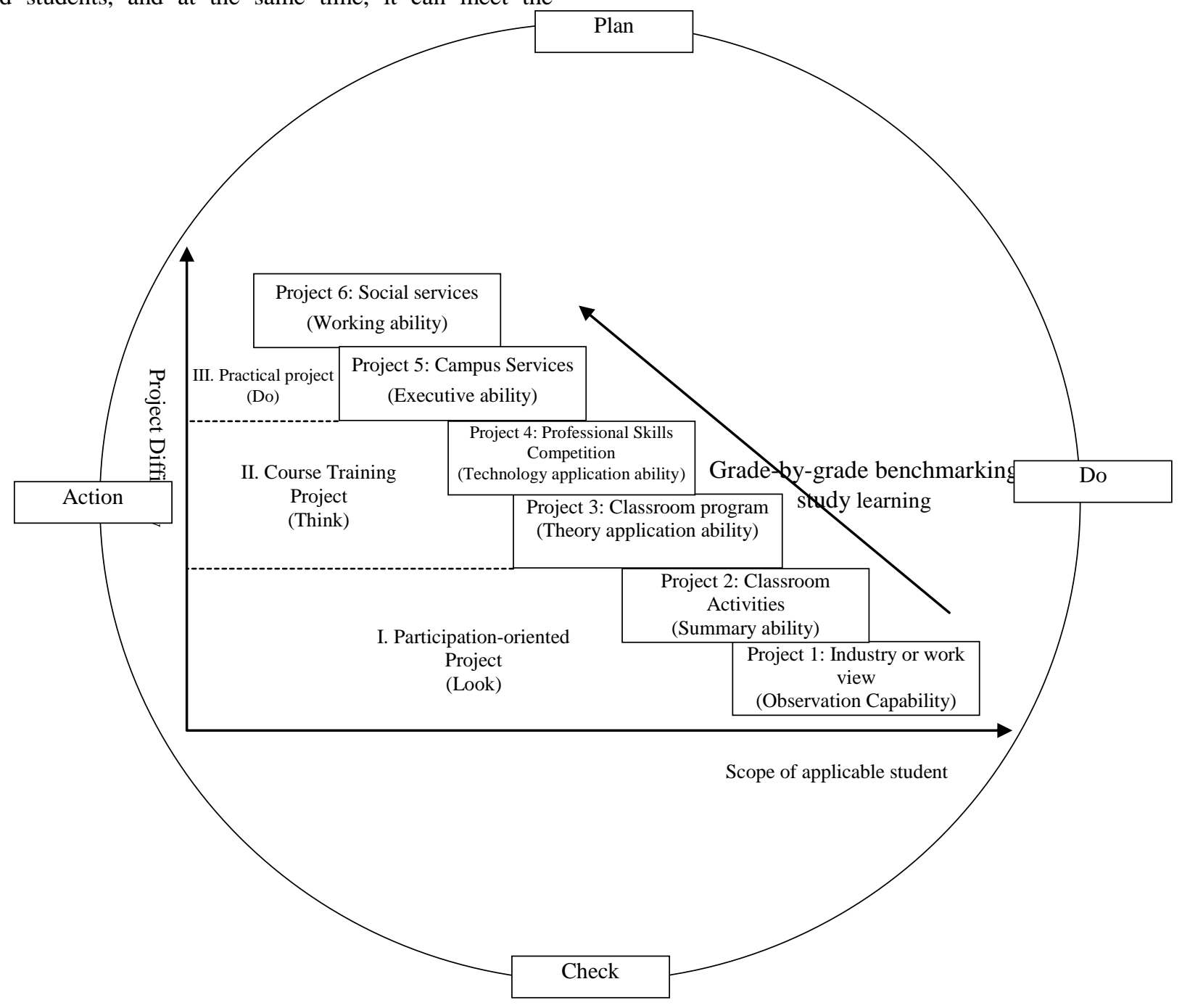

Fig. 1. Staircase constructed project-oriented teaching method from the perspective of total quality management.

1) Participation-oriented projects: The class-I projects are participation-oriented project, which are mainly to train students' ability of "look". Such projects are divided into two phases.

At the watching and learning stage of industry or work, students visit the enterprise and work site involved in subject knowledge system to understand the industry and professional situation, while teachers explain relevant knowledge and information and observe the students' learning ability, providing the basis for later targeted teaching.

During the course of classroom activity, students recall the process of watching and learning, summarize and share the information, raise questions and discuss them. This teaching project can deepen students' perception of industry or work, arouse their thinking on the profession and industry, promote the communication between teachers and students, and enhance the students' abilities of language expression and summary.
The class-I projects, which are with the lowest difficulty, are the most basic teaching projects for development of students' abilities of observation and summary, and are suitable for students with any learning base and learning ability. After the students complete the study of class-I, they will enter the study of class-II projects.

2) Course training projects: The class-II projects are course training class projects, which are mainly to cultivate students' ability of "Think". Such projects are divided into two phases as well.

At the stage of the classroom program, the teachers assign the students with the course training tasks guided by the work process and the problem-solving in accordance with the objectives of the project teaching ability training, participated in by students in the whole course, to strengthen the professional knowledge and skills in the course of completing 
the tasks, and apply the theoretical knowledge to the scheme design.

At the stage of professional skill competition, for students who present outstanding scheme design at the stage of the classroom program, the teacher will continue to guide them for improvement in combination with their learning abilities and willingness to participate in professional competition. So that students can not only exploit their own potential abilities through the competition, but also can see the performance of their opponents in the field, to realize the distance between themselves and the excellent students, and stimulate their desire to continue to make efforts.

The class-II projects are with moderate difficulty, and students' professional skills can be practiced in simulated work situation. The average students can learn and strengthen basic knowledge and skills through this class of teaching projects, and can apply them to professional skill course training and competition. It is also possible for the less-advanced students who have passed class-I projects to make achievement. After completing this class of project, the first-class students will have more questions and thoughts and look forward to the study of class-III projects.

3) Practical projects: The class-III projects are practical projects, mainly training students' ability of "do" .Such projects are divided into two stages.

At the school service stage, the professional teachers design the school service teaching projects by use of the campus resources, which can test the students' understanding of skills, exercise executive ability and increase practical experience by relying on the professional student associations.

At the stage of social service, the professional teachers find some opportunities for students of off-campus job practice by visiting the industry enterprises. The students' skills in the classroom will be fully applied to the real work scene, testing their learning achievement in the practice, and improving their working ability.

The class-III projects have the highest degree of difficulty, and students can improve their ability to execute and work during the service process. This kind of teaching project can display the working skills of the excellent students, stimulate the enthusiasm of the middle school students, set up the learning model for the students, and is the ultimate goal of the project-oriented teaching. Upon completion of the study work of the project, students have necessary basic skills and can go to work with confidence.

\section{B. Ability Promotion Path under the Guidance of Benchmarking Study Method}

1) Establishment of benchmarking study method: Benchmarking study method is an effective way to play an example role, a learning method to affect people's thoughts, feelings and behaviors through excellent qualities of excellent characters. Modeling has the characteristics of image, vividness, truth and so on, and it can embody the abstract morality through example model, which is easy to understand and study.

In this study, with the upgrade of teaching phase, the difficulty of teaching project gradually increases. In order to improve the students' ability in a stable manner, this study establishes a benchmarking study method. In relation to the students themselves, by taking students or competitors who have completed the higher-stage teaching projects as benchmarking study object, they can improve their professional abilities in comparison with the excellent quality of the modeling.

2) Selection of parth to improve student's abilities: In the benchmarking study method, the selection of the benchmarking study object is the key factor to the effective promotion of the student's ability. In order to improve the students' learning skills stably, the study aims at decomposing the ultimate goal according to the difficulty level, and puts forward the promotion path of the grade-by-grade benchmarking study ability. That is, students who are at each stage of competence are learning objects in a higher stage, and when their own ability reaches the target learning object, carry out the next stage of benchmarking study, repeat it and then realize the ultimate goal of the project teaching - possessing the social service ability.

3) The status of teachers in benchmarking study: Under the guidance of grade-by-grade benchmarking study method, some students will reach the goal of talent cultivation at the 6 th stage before graduation. At this time, teachers need to become part of the students' benchmarking study object by virtue of their professional skills and practical experience. Therefore, teachers need to strengthen professional skills through continuous learning, understand professional front information, need to be in-depth enterprise line, cultivate professional ability and professional accomplishment in practice, constantly pursue self-improvement, ensure that they can possess the quality of target object, so as to excite the learning motivation of outstanding students and lead the outstanding students to pursue excellence.

\section{Project Management Based on Total Quality Management Ideas}

In this study, both teachers and students participate in the project management. When conducting design of teaching project, selection of benchmarking study object and evaluation of project teaching effect, the teachers and students, guided by total quality management idea, using PDCA as the working procedure, propose plans, implement schemes, find out problems and solve problems and repeat. In repeating process, the quality of the project management is climbing up in a steplike way. 
1) Application of PDCA Cycle in teaching project design: At the planning stage, the teacher can master the situation of students and the courses, determines the main target of the ability training, and develops the teaching project design plan according to the learning situation analysis and the teaching resource analysis. At the stage of execution, the teachers design the teaching project according to the plan, and compare the design content with the training target of the course at the inspection stage. Based on the comparison result, the teaching project is optimized. Other unsettled problems occurring during the optimization process will enter the next cycle, as shown in "Fig. 2".

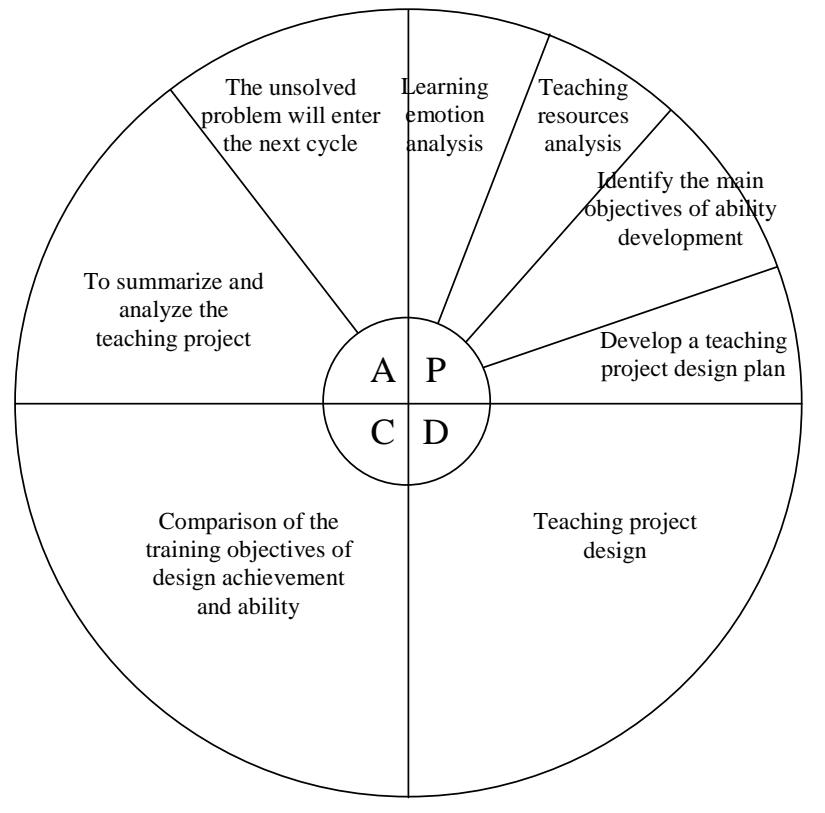

Fig. 2. Application of PDCA Cycle in teaching project design.

2) Application of PDCA Cycle in grade-by-grade benchmarking study

Based on the self-competence cognition and the target ability level, the students develop the plan for selection of the target learning object. After selecting the target learning object according to the plan, the ability of the target learning object is compared with the targeted ability level requirements, then reconsider the accuracy of the selection of the object, and adjust. The unresolved problem will enter the next cycle. As shown in "Fig. 3".

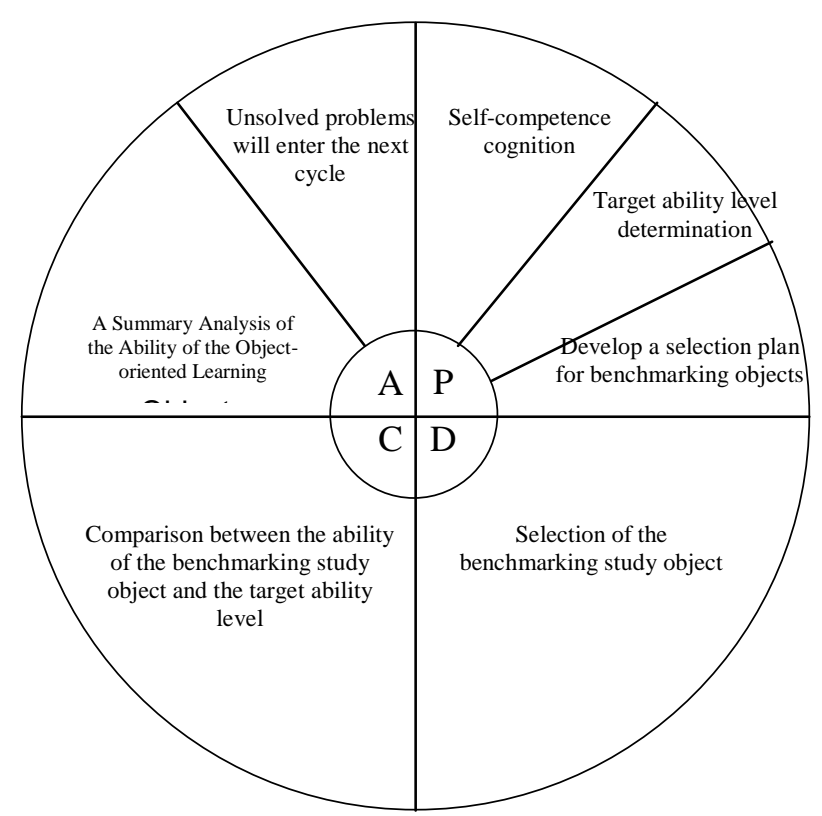

Fig. 3. Application of PDCA Cycle in grade-by-grade benchmarking study.

3) Application of PDCA Cycle in the evaluation of project teaching effect

After the completion of the project teaching, the teachers and students jointly evaluate the teaching effect. Firstly, on the basis of the training goal of the project teaching ability, the teacher develops the plan of project teaching effect evaluation to evaluate the project completion and the ability improvement of the students. After the evaluation results come out, further talk with the students being evaluated, summarizes and analyzes the evaluation results through comparison with the students' actual proficiency. For other unsolved problems that occur during the optimization process, they will enter the next cycle, as shown in "Fig. 4. 


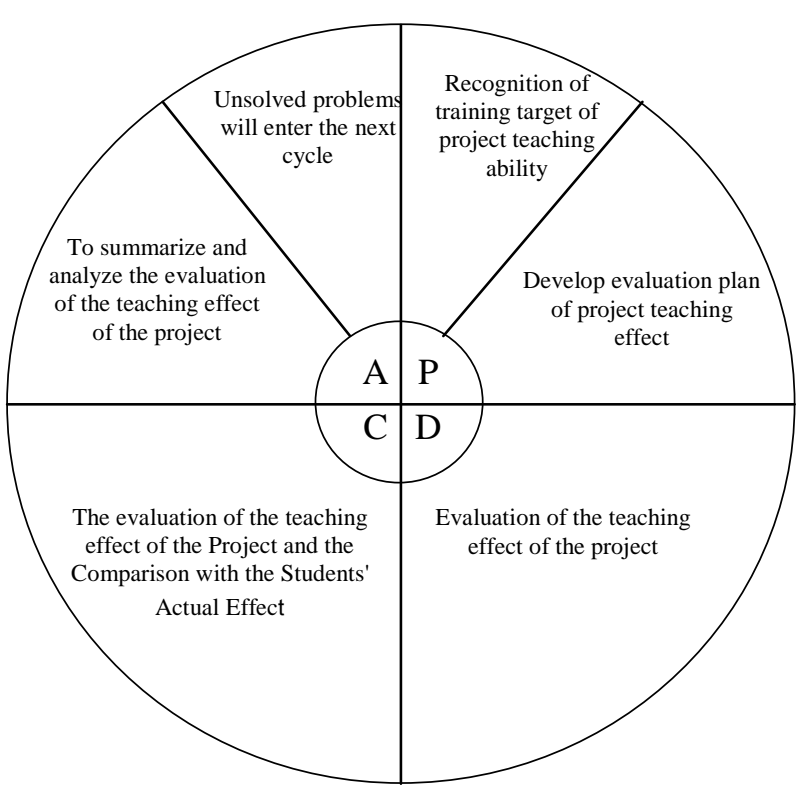

Fig. 4. Application of PDCA Cycle in the evaluation of project teaching effect.

\section{SignificANCE OF StairCASE CONSTRUCTED PROJECT- ORIENTED TEACHING METHOD FROM THE PERSPECTIVE OF TOTAL QUALITY MANAGEMENT}

\section{A. Optimization of Development Mode of the Application- Oriented Technical Talents}

The design of staircase constructed teaching project meets the practice and practical needs of students at different levels, expands the scope of application of traditional project-oriented teaching method, and provides a preliminary solution idea for the "acclimatized" issue of German type "project-oriented teaching method" in the development of Chinese applicationoriented technological talents; the benchmarking study method, which embodies an abstract professional ability through an example model, is easy to understand and study, and it broadens the visual field of the students, allows them understand the direction of effort, enhance the crisis consciousness of the students; the comprehensive quality management thought guides the whole process of the project management, both teachers and students participate in the design of the teaching project, and guarantee the standardization and normalization of the project management process in the whole process of the selection of the target object and the evaluation of the teaching effect of the project. In conclusion, this teaching model optimizes the traditional teaching method, and raises the training quality of applicationoriented technological talents.

\section{B. Promoting the Construction of Multi-level Practical Training Base}

The Staircase Constructed teaching project consists of various projects with different difficulty levels and ability training levels. In order to build the project staircase, the teacher team needs to actively promote the construction of offcampus practical training base; to build practical teaching projects based on competition and in-campus resources through professional skill competitions and in-campus production practices at all levels; to form professional associations, invite the industry enterprise professionals to campus for knowledge skills discussion salon, hold special lectures, and communicate with the students; to lead the students to go into the field of business enterprise work and industrial exhibition for field visit The teaching team promotes the construction of multi-level practical training base from the campus to the society, simple to complex, the foundation to the advanced multi-aspect project teaching scene.

\section{Strengthening the Construction of Teacher Team}

The teacher is more the benchmarking study object of students who are equipped with "working ability" than the researcher of this teaching model. The attention and benchmarking requirement of the students raise higher requirements for the teachers. Teachers need to strengthen their study in the field of professional research by hosting and participating in scientific research projects; through continuous learning in professional fields, to expand their breadth of professional knowledge and skills; and through serving enterprises, to understand the production process of enterprises and accumulate professional experience. The undertaking of scientific research projects, the exploration of the depth of the professional knowledge and skill areas, the development of the breadth and the participation of the production practice process of the enterprise not only make the teachers become students' "Qualified Benchmarks", but also promotes the improvement of teachers' scientific research ability, the depth of professional study and the enhancement of ability to serve enterprise and strengthen the construction of teacher team.

\section{THE PROMOTION OF STAIRCASE CONSTRUCTED PROJECT-ORIENTED TEACHING METHOD FROM THE PERSPECTIVE OF TOTAL QuALITY MANAGEMENT}

\section{A. Promotion Conditions of Teaching Mode}

Implementation of teaching work by use of staircase constructed project-oriented teaching method from the perspective of total quality management needs to meet the following conditions, which are open to all disciplines and courses.

First, the discipline or course is allowed to use the projectoriented teaching method to carry out the teaching work;

Secondly, the discipline or course is mainly to train the application-oriented technological talents under theory guiding practice.

Thirdly, the learning abilities of the teaching objects are different.

\section{B. Possible Problems in the Application of the Teaching Mode}

1) Poorlearning enthusiasm of the students: Some students have little contribution to the team when the project is 
completed in a cooperative manner; when the project is completed in an individual way, the quality of the project is low with no or little progress.

2) High learning enthusiasm of the students, but with few valuable gains: Some students, who are interested in projectoriented teaching and benchmarking study, are very willing to complete the project-oriented study task, but when sharing experience, they only talk about more about study will and fun, but less professional cognition or skill training experience less. "They are more interested in the form instead of the core", which has no substantial contribution to the improvement of students' ability and the cultivation of vocational quality.

\section{Countermeasures}

1) Optimization of the structure of project-oriented study team: As for the team study project, the number of team members should be reduced to $2-3$, and aiming at the characteristics of the students, arrange the learning tasks to individual after the project learning tasks are decomposed; for the individual learning project, reduce the learning difficulty as far as possible under the premise of ensuring the basic capability training.

2) Elaborating project-oriented teaching requirements and reform "questions and answers" to "multiple choice questions": The reason for the students learning less is that it is not enough to grasp the overall teaching purposes of the teaching project comprehensively, and it is relatively weak to draw instance. Therefore, the teachers need to further elaborate the teaching requirements of the project, refine the training objectives, and request the students to refer one by one and share their achievements.

\section{CONCLUSION}

Strongly driven by increasing demand for applicationoriented technical talents in China, the project-oriented teaching method still plays an important role in the practice of talent training. However, the staircase constructed projectoriented teaching is undoubtedly one of the effective ways to improve the students' application skills, according to the situation of Chinese application-oriented technological school students. The management of project-oriented teaching process under the total quality management is the key to ensure the effectiveness of staircase constructed project. In practical teaching, staircase constructed project-oriented teaching will make it difficult to conduct teaching organization to certain degree. Therefore, in order to ensure the realization of the teaching method and create an environment suitable for the cultivation of application-oriented talents, it needs enterprises, colleges and teachers to overcome the difficulties and work together.

\section{REFERENCES}

[1] Lei Qing, Yuan Jian. A View of Application-oriented Technological Talents from the Perspective of National Innovation System[J]ChinaHigher Education, 2015, (22): 34-36.
[2] Lin Jiangyong, Wei Nongjian, DuanMingming. Project-oriented Teaching: the Choice of Application-oriented Teaching Mode[J]. China University Teaching, 2010, (10): 33-35.

[3] Pan Chunsheng, Liu Dan. Rational Thinking of "Project-oriented Teaching Fever" in Vocational Education [J]. ChinaHigher Education Research, 2011, (05): 76-78.

[4] Sun Jinquan. Research on the Value of Benchmarking Study in Ideological and Political Work of College Students[J].Education and Cultivation, 2016, (24): 44-45. 